\title{
Role of humus substances in the formation of the soil geochemical fluxes during deposit exploitation in Okhotsk region
}

\author{
Makhinova A.F., Makhinov A.N. \\ Institute of Water and Ecology Problems, Far Eastern Branch of the Russian Academy of \\ Sciences, Khabarovsk, Russia, mahinova@ivep.as.khb.ru
}

Keywords: humus, soils geochemical fluxes, elements, mining

doi: 10.36291/HIT.2019.makhinova.038

The mechanisms involved in the formation of the soil geochemical fluxes are dependent on the physical state of the solid, liquid and organic soil phases. The synthesis and decomposition of organic matter and the formation of the finely dispersed and soluble humic acid fractions play an important role. The geochemical processes in soils occur as a result of three forces: (1) the adhesion or the mutual molecular attraction between fine particles less than 2-3 $\mu \mathrm{m}$ in size, thus resulting in their coagulation and aggregation into the $<1 \mu \mathrm{m}$ fractions (the effect of sorption); (2) the molecular absorption of water onto the surface of fine particles of the solid and organic soil phases, which causes soil swelling (the effect of water intake); (3) the molecular interaction between the soil phases and gravity moisture promoting the dissolution and removal of weathering products.

Excess water in soil pores will tend to mix with elements and their compounds to form soil solution, which move through the pore space due to gravity formation the soil geochemical fluxes. The interaction between the aggressive humic acid fraction and the soil microorganisms results in the formation of complex cations $\left(\left[\mathrm{FeHSO}_{4}\right]^{+},\left(\left[\mathrm{FeHSO}_{4}\right]^{2+}\right.\right.$, $\left(\left[\mathrm{CuHSO}_{4}\right]^{+}\right.$and protons $\left(\left[\mathrm{H}^{+}\right]\right)$in soil pores. With increasing $\mathrm{pH}$ in the solution $(<3.5)$, complex salts dissociate to give high-charge cations $\left(\mathrm{Fe}^{2+(3+)}, \mathrm{Cu}^{2+}, \mathrm{Zn}^{2+}, \mathrm{Pb}^{2+}\right)[1]$. In the presence of free oxygen, the oxidizing properties of manganese effect the dissociation of $\mathrm{Co}^{2+}$ and $\mathrm{Co}^{3+}$. Such components are indicative of hypergene conditions within the Okhotsk region. The concentrations of elements in the soils correlate with the organic matter content and particle-size distribution.

Two types of geochemical migration fluxes were identified in the background: (1) $\mathrm{N}-$ natural and (2) A - anthropogenic. The natural migration fluxes are directed vertically downward the soil profile and assist the subsurface exchange of substances.

The anthropogenic migration fluxes are related to areas of mining operations. The waste produced during open-pit mining and other mining and smelting operations in a source of soil contamination with heavy metals. After being exposed to air, the oxidation of sulfide-bearing minerals takes places according to the following reaction: $2 \mathrm{FeS}_{2}$ (pyrite) + $2 \mathrm{H}_{2} \mathrm{O}+7 \mathrm{O}_{2}=2 \mathrm{FeSO}_{4}+2 \mathrm{H}_{2} \mathrm{SO}_{4}$, with the formation of unstable iron sulfates [2]. The products of the mineral degradation and the fine particles of weakly oxidized mineral substances are transported down the slopes with the rain water runoff and form the anthropogenic migration fluxes.

The concentrations of heavy metals are generally high in the vicinity of each mining site, which represents the zone affected by mining lying within a $200-500 \mathrm{~m}$ radius depending on the natural conditions.

We thank I.V. Perminova, Doctor of Sciences (Chemistry) and Professor of Moscow State University, Faculty of Chemistry, for valuable advices in this work.

References

1. Senesi N., Poffredo E. // In: "Chemical Processes in Soil”, Soil Sci. Soc. Amer., Madison, 2005, 563-617.

2. Makhinova A.F. et al. // J. Geochem. Exploration. 2013. 132:140-148. 